\title{
Landscape analysis of the family planning situation in Pakistan-District profile: Peshawar
}

Population Council

Follow this and additional works at: https://knowledgecommons.popcouncil.org/departments_sbsr-rh

Part of the Demography, Population, and Ecology Commons, Family, Life Course, and Society Commons, and the International Public Health Commons How does access to this work benefit you? Let us know!

\section{Recommended Citation}

"Landscape analysis of the family planning situation in Pakistan-District profile: Peshawar." Islamabad: Population Council, 2016. 


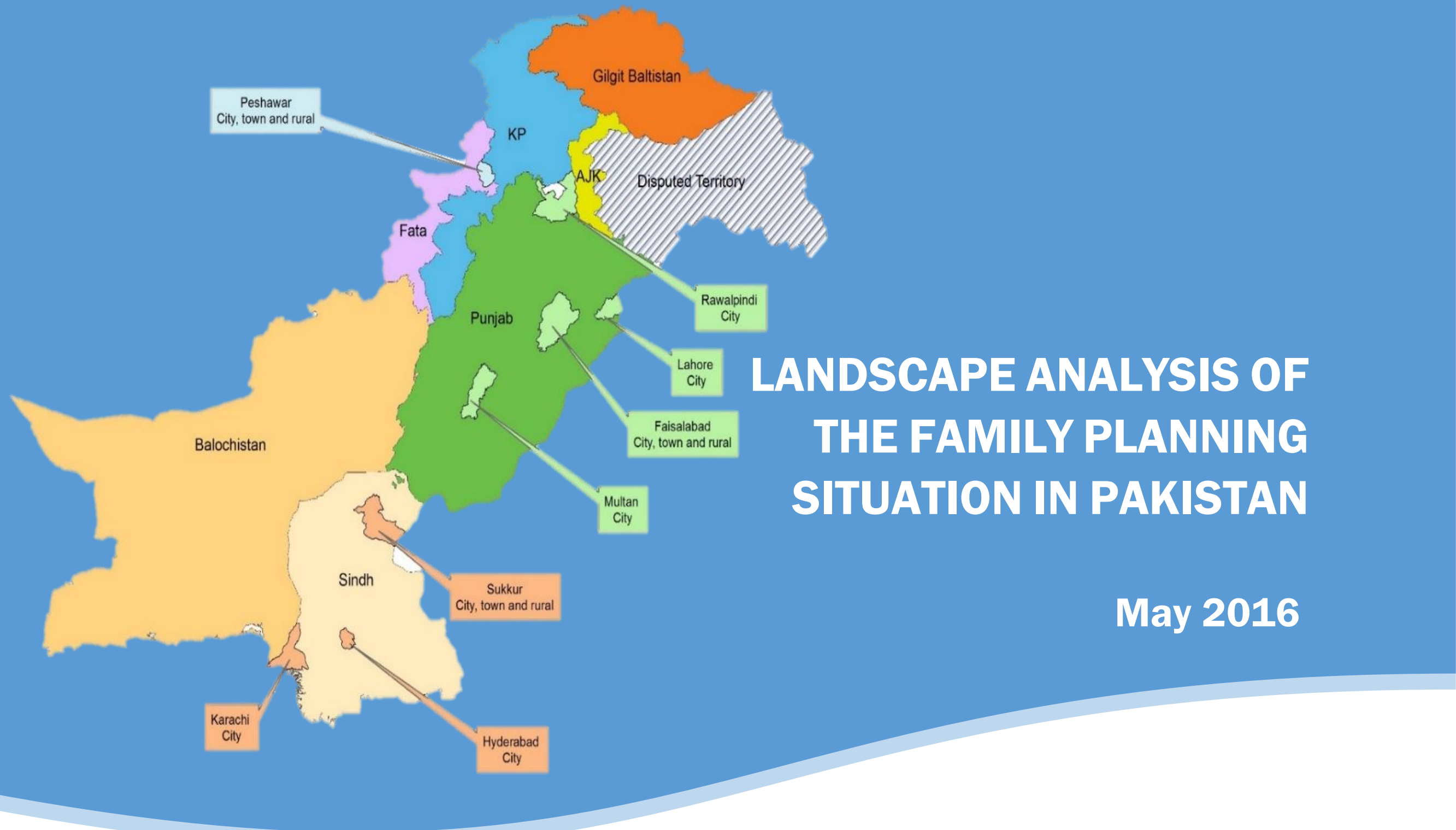

\section{DISTRICT PROFILE: PESHAWAR}

BILL\& MELINDA

GATES foundation
POPULATION COUNCIL

Ideas. Evidence. Impact. 


\section{Background}

Peshawar is situated in the center of Khyber Pakhtunkhwa (KP) and is the largest city and capital of the province. It has an estimated population of 3.7 million. ${ }^{1} \mathrm{~A}$ map of the district is presented in Figure 1.

Table 1 presents key demographic facts about the district. About 52 percent of Peshawar's population resides in urban areas. Of the estimated 0.6 million women of reproductive age (MWRA) in the district, 0.3 million lives in urban areas.

The total fertility rate in Peshawar is $4.02,{ }^{2}$ which is slightly higher than KP's average of 3.9. The infant mortality rate is 58.

Table 1: Demographics of Peshawar

\begin{tabular}{|l|l|l|l}
\hline Demographics & Urban & Rural & Overall \\
\hline Total population & $1,725,000$ & $1,977,000$ & $3,702,000$ \\
\hline Women, 15-49 years & 424,000 & 468,000 & 892,000 \\
\hline MWRA & 280,000 & 331,000 & 611,000 \\
\hline $\begin{array}{l}\text { Literacy rate (10 } \\
\text { years and above)* }\end{array}$ & $68 \%$ & $52 \%$ & $61 \%$ \\
\hline IMR (KP)** & - & - & 58 \\
\hline TFR** & - & - & 4.02 \\
\hline SOurc: KP development
\end{tabular}

Source: KP development Statistics 2014, * Pakistan Social and Living

Standards Measurement Survey (PSLMS) 2014-15, ** Pakistan

Demographic and Health Survey (PDHS) 2012-13

The contraceptive prevalence rate in Peshawar is 48.6 percent, ${ }^{3}$ which is much higher than KP's average (28\%). However, it includes high use of traditional methods, both in urban and rural areas (Table 2).

\section{Figure 1: Map of Peshawar District}

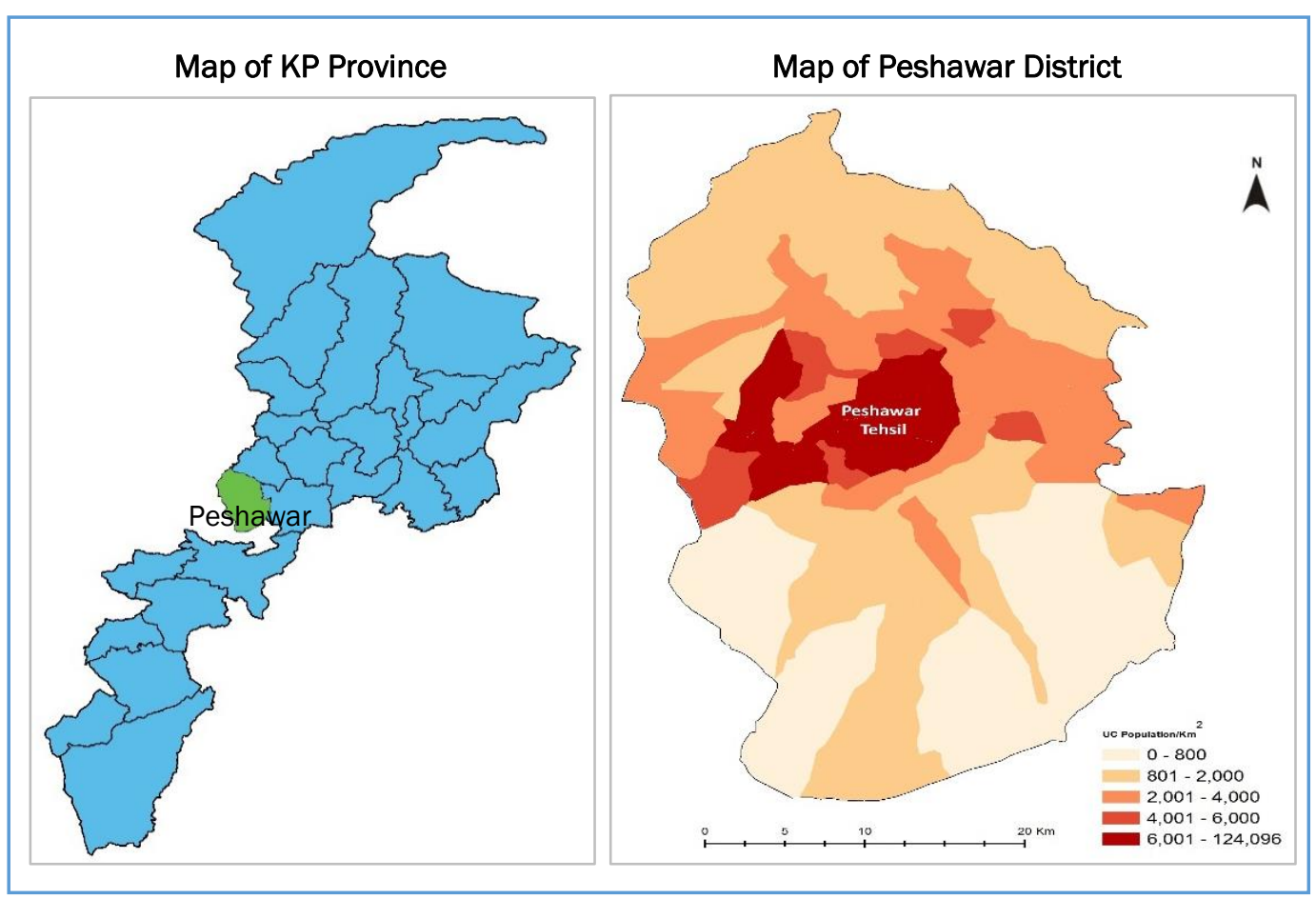

Table 2: Contraceptive Use and Unmet Need

\begin{tabular}{lllll}
\hline & \multicolumn{3}{c}{ Contraceptive Prevalence Rate (CPR) } \\
\cline { 2 - 4 } District & Any Method & Traditional Methods & Modern Methods & Unmet need \\
\hline Peshawar & 48.6 & 22.4 & 26.2 & 16.9 \\
Urban & 49.5 & 21.2 & 28.3 & 17.5 \\
Rural & 47.2 & 24.1 & 23.1 & 16.0 \\
\hline
\end{tabular}

Source: Pakistan Demographic and Health Survey (PDHS) 2012-13 
Among users, method preferences vary by urban/rural residence (Figure 2). Condoms and withdrawal are the most popular methods, with the former relatively more popular in urban areas and the latter in rural areas. IUDs and female sterilization are more popular in urban areas, while pills and the lactational amenorrhea method (LAM) are more used in rural areas. Unmet need is 16.9 percent, a bit higher in urban than rural areas.

Figure 2: Contraceptive use by method and place of residence

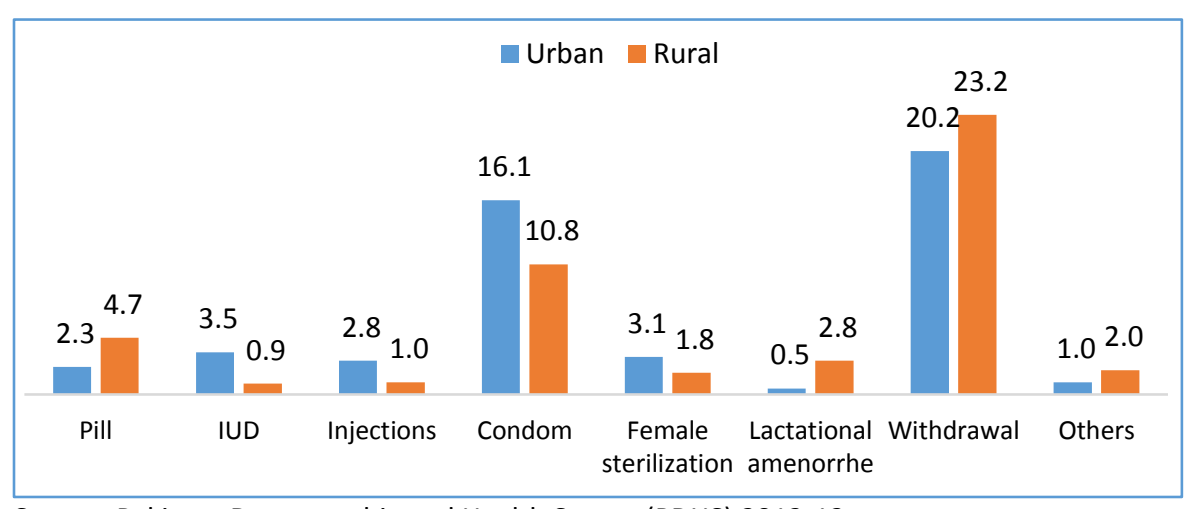

Source: Pakistan Demographic and Health Survey (PDHS) 2012-13

\section{Use of Antenatal and Dellvery Care Services}

The majority of women in Peshawar sought antenatal health care from a skilled provider during their last pregnancy (81\%). 4 However, the proportion of women who sought antenatal health care is much higher in urban areas (88\%) than in rural areas (73\%).

In both urban and rural areas, the public sector is the major source of antenatal health care, although the proportion of women utilizing the public sector is much higher in urban areas (47\%). While the majority of deliveries take place at a health institution, the proportion of such deliveries is much higher in urban areas (86\%) than in rural areas (62\%). Public sector facilities comprise the major place of delivery in urban areas (55\%), while in rural areas, home is the major place for deliveries (38\%).

\section{Other Soclo-economlc Indlcators}

The literacy rate (10 years and above) in Peshawar is 61 percent. However, the urban literacy rate is 16 percentage points higher than the rural literacy rate (68\%). Female literacy rate is much lower in both urban and rural areas (urban $51 \%$, rural $31 \%)$.
The majority of households own a television set (73\%), but urban-rural differences are huge, with 86 percent of urban households having a TV set compared to only 58 percent of rural households. Mobile or land line phones are owned by the vast majority of households (98\%), with minor urban-rural differences.

In terms of building materials, the majority of houses in urban areas (77\%) have roofs made of reinforced cement concrete(RCC) or reinforced brick concrete(RBC), while in rural areas, most houses use wood or bamboo (56\%). Burnt bricks or blocks are used as the main material for house walls in both urban and rural areas, although a large proportion of rural houses do use mudbricks or mud (34\%). These indicators show, urban households have fairly good socioeconomic conditions than rural households.

\section{Avallabillty of Health Facilities, Pharmacies and LHWs}

During the family planning landscape assessment, a census of public and private health facilities and pharmacies was carried out in Peshawar district. Figure 3 shows the breakdown of public and private health facilities in urban and rural areas. Pharmacies account for a larger share in urban areas (67\%) and Lady Health Workers (LHWs) in rural areas (32\%). A good proportion of LHWs is also available in the urban areas (15\%). There are more facilities of the Department of Health (DoH) in the urban areas, while facilities of the People's Primary Healthcare Initiative (PPHI) are only present in the rural areas as $\mathrm{P}$
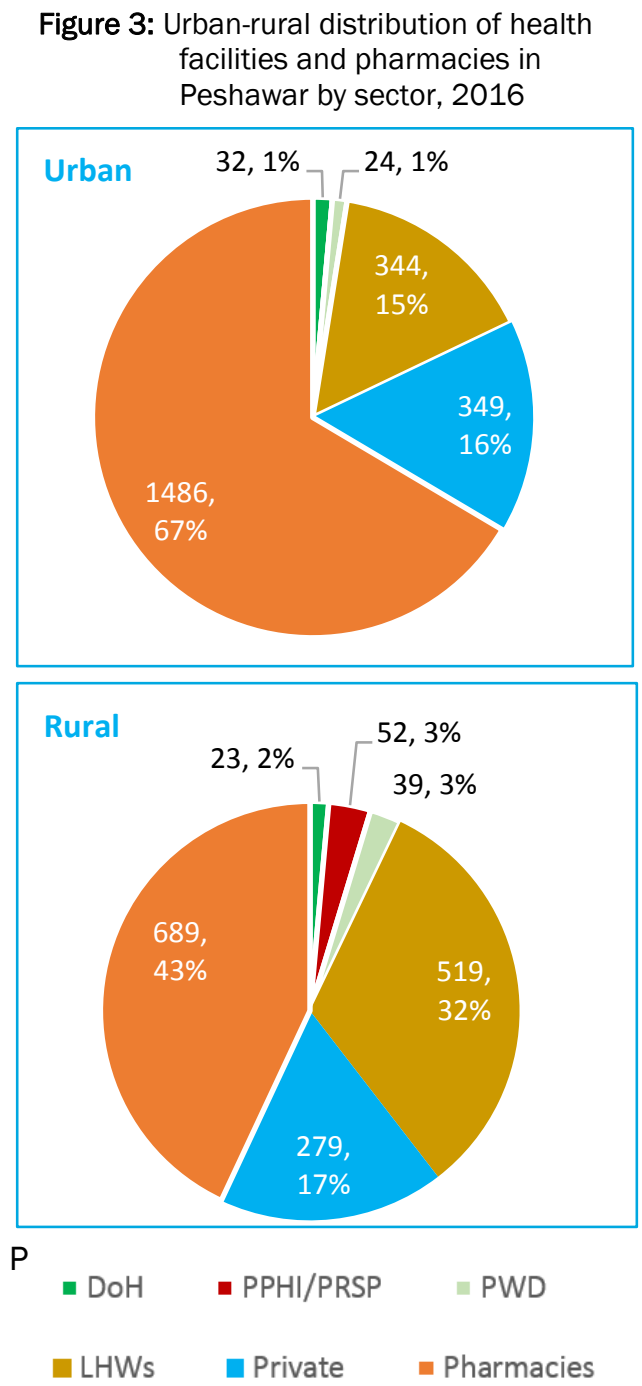

${ }^{4}$ Pakistan Social and Living Standards Measurement Survey (PSLMS) 2014-15 


\section{Distribution of Public Health Facilities by Cadre}

Figure 4 shows distribution of static public health facilities in urban and rural areas of Peshawar. In urban areas, Family Welfare Centers (FWCs) are more numerous (36\%), followed by dispensaries (34\%), and public hospitals (14\%). In rural areas, facilities of PPHI are more numerous (46\%), followed by FWCs (34\%).

Figure 5: Cadre-wise urban-rural distribution of static public facilities in Peshawar, 2016
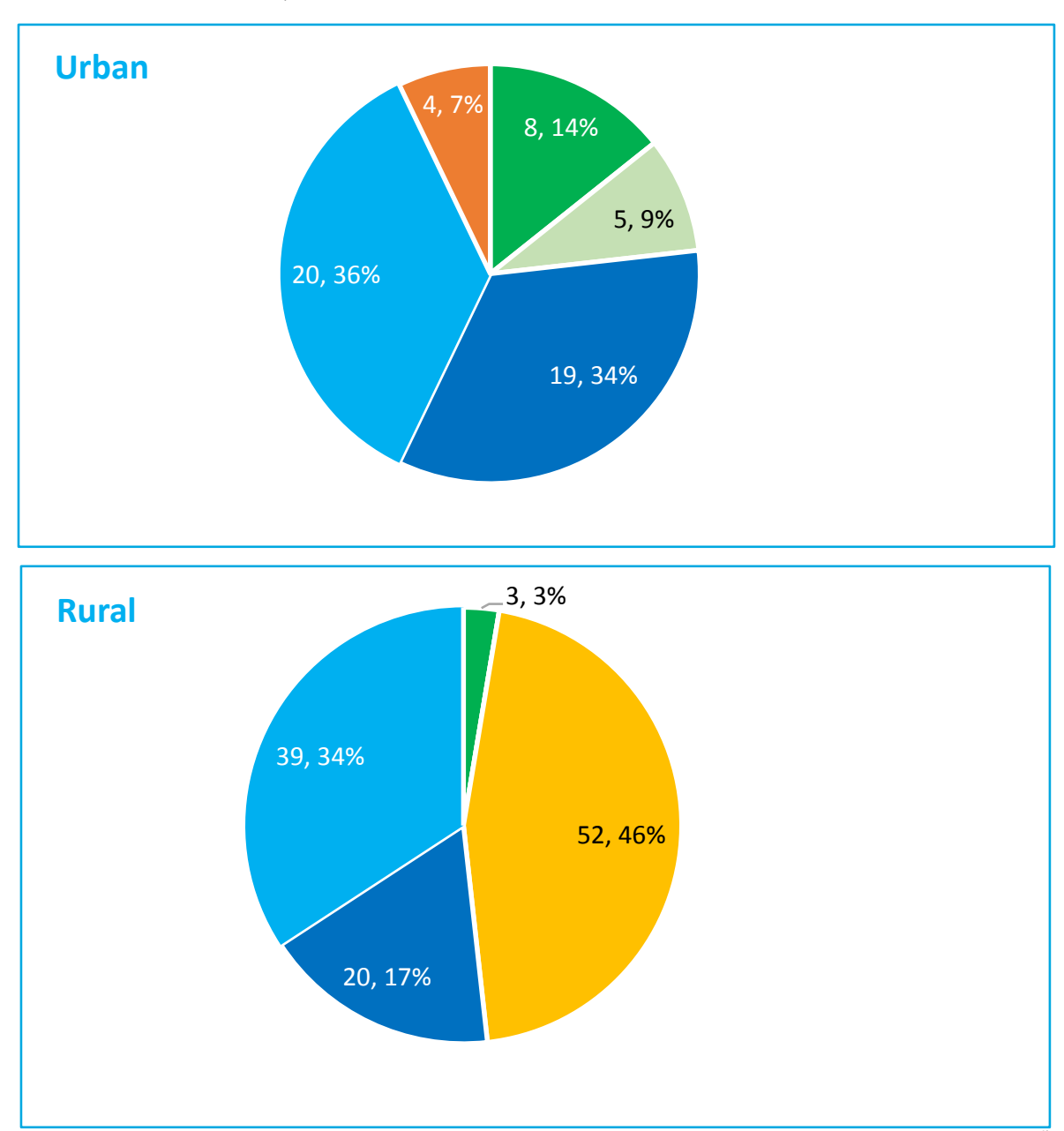

- Public Hospitals = MCH/Maternity Centers $=$ PPHI/PRSP - Dispensaries a FWCs a RHSC-A/FHCs

\section{Distribution of Private Facilities by Cadre}

Figure 6 shows the distribution of private facilities in urban and rural areas of Peshawar. In urban areas, private hospitals are largest in number (27\%), followed by clinics of male doctors (23\%), and homeopath/hakeem clinics (18\%). In rural areas, clinics of dispensers are present in the largest numbers (50\%), followed by clinics of male doctors (21\%), and private hospitals (16\%). Clinics of female providers account for a much higher proportion of health facilities in urban areas than in rural areas.

Figure 6: Cadre wise urban-rural distribution of private facilities in Peshawar, 2016
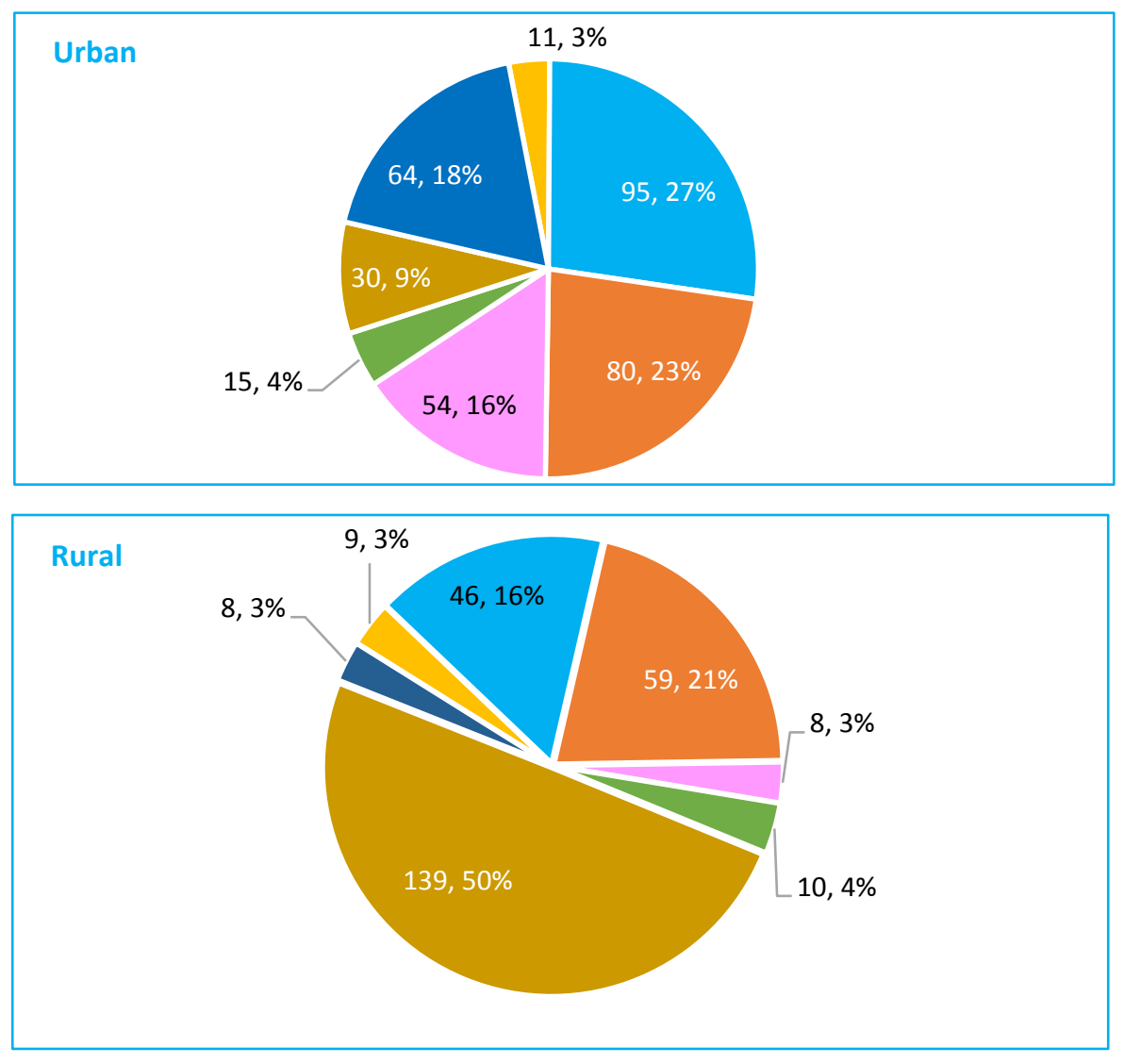

= NGO Clinics

- Male Doctor Clinics

- LHV/Nurse/Midwife Clinics

- Homeopath/Hakeem Clinics
- Private Hospitals

= Female Doctor Clinics

- Dispenser Clinics 


\section{Provision of Specific Family Planning Methods by Sector}

Table 3 shows the proportion of different sectors providing specific family planning methods in urban and rural areas of Peshawar. Facilities of DoH are providing most methods, but mostly in the urban areas, and the proportion of facilities providing is quite low. Facilities of the Population Welfare Department (PWD) are also providing most methods. LHWs are almost fully providing the three methods in their repertoire, i.e., condoms, pills and the second/subsequent dose of injectables. Notably, this cadre has a huge potential for providing the first dose of injectables and emergency contraceptive pills (ECPS) as well.

Private facilities are considerable in numbers but only a small proportion $(<30 \%)$ are providing any method in both urban and rural areas.

Table 3: Provision of specific family planning methods in Peshawar by sector, \%, 2016

\begin{tabular}{|c|c|c|c|c|c|c|c|c|c|c|c|c|c|c|c|c|c|c|}
\hline \multirow[b]{2}{*}{ Sector } & \multicolumn{2}{|c|}{ Condoms } & \multicolumn{2}{|c|}{ OCPs } & \multicolumn{2}{|c|}{ Injectables } & \multicolumn{2}{|c|}{ IUDs } & \multicolumn{2}{|c|}{ ECPs } & \multicolumn{2}{|c|}{ Implants } & \multicolumn{2}{|c|}{$\begin{array}{c}\text { Female } \\
\text { Sterilization }\end{array}$} & \multicolumn{2}{|c|}{$\begin{array}{c}\text { Male } \\
\text { Sterilization }\end{array}$} & \multicolumn{2}{|c|}{$\begin{array}{l}\text { Number of } \\
\text { Facilities/ } \\
\text { Pharmacies }\end{array}$} \\
\hline & U & $\mathrm{R}$ & U & $\mathrm{R}$ & U & $\mathrm{R}$ & U & $\mathrm{R}$ & U & $\mathrm{R}$ & U & $\mathrm{R}$ & U & $\mathrm{R}$ & U & $\mathrm{R}$ & U & $\mathrm{R}$ \\
\hline DoH & 34 & 9 & 44 & 13 & 44 & 9 & 28 & 9 & 22 & 0 & 6 & 0 & 13 & 0 & 3 & 0 & 32 & 23 \\
\hline PPHI/PRSP & - & 56 & - & 52 & - & 52 & - & 42 & - & 17 & 0 & - & 0 & - & 0 & - & 0 & 52 \\
\hline PWD & 100 & 100 & 100 & 100 & 100 & 100 & 100 & 100 & 38 & 8 & 17 & 0 & 17 & 0 & 4 & 0 & 24 & 39 \\
\hline LHWs & 100 & 100 & 100 & 100 & 100 & 100 & NA & NA & NA & NA & NA & NA & NA & NA & NA & NA & 344 & 519 \\
\hline Private & 23 & 13 & 31 & 21 & 27 & 16 & 9 & 6 & 9 & 3 & 1 & 0 & 5 & 0 & 1 & 0 & 349 & 279 \\
\hline Pharmacies & 25 & 38 & 38 & 37 & 15 & 16 & 0 & 0 & 11 & 7 & 0 & 0 & NA & NA & NA & NA & 1486 & 689 \\
\hline
\end{tabular}

NA: Not applicable, U: Urban, R: Rural

ECP: emergency contraceptive pill, IUD: intrauterine device, OCP: oral contraceptive pill 


\section{Presence and Provision of FP Services/Products: A Comparison}

Figures 7, 8 and 9 present pairs of maps showing the presence of public health facilities, private health facilities, and pharmacies, respectively, and actual provision of family planning services/products by each category. Figure 7 presents an encouraging picture of family planning service provision by nearly all of the 170 public health facilities.

Figure 7: Proportion of public static health facilities providing at least one FP service, 2016
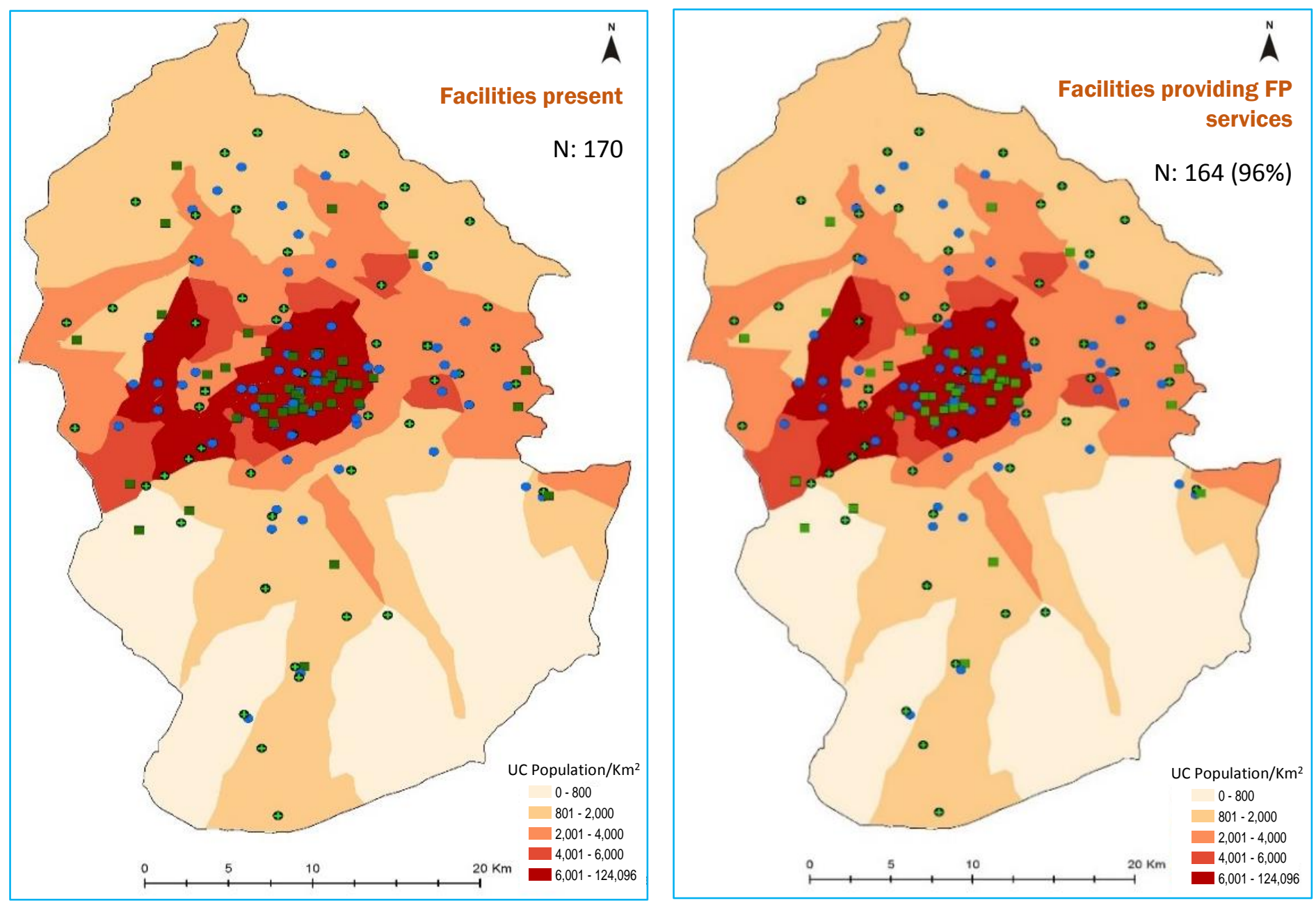

Department of Health $(\mathrm{DoH})$

- People's Primary Health Care Initiative (PPHI)

- Population Welfare Department (PWD) 
Among private health facilities, the proportion providing family planning services drops to about a third (Figure 8). However, in terms of numbers, nearly twice as many private facilities are providing some family planning services as public facilities.

Figure 8: Proportion of private health facilities providing at least one FP service, 2016
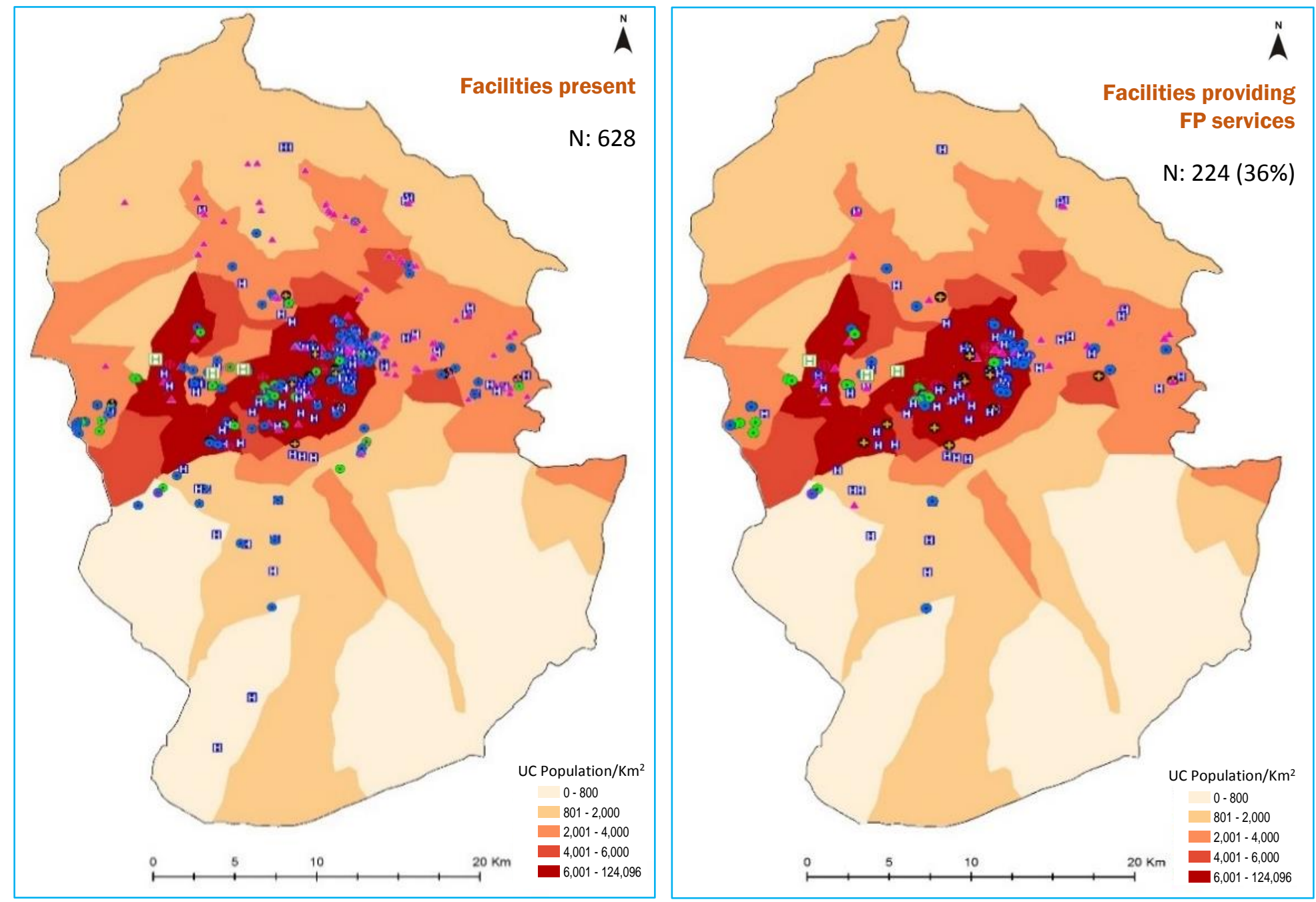

(1) Private Hospitals

- LHV/Nurse/Midwife Clinics

- Male Doctor Clinics

4. Dispenser Clinics

- Female Doctor Clinics $\oplus$ Homeopath/Hakeem Clinics 
Slightly less than half of the pharmacies in the district are selling at least one FP product (Figure 9).

Figure 9: Proportion of pharmacies selling at least one FP product, 2016
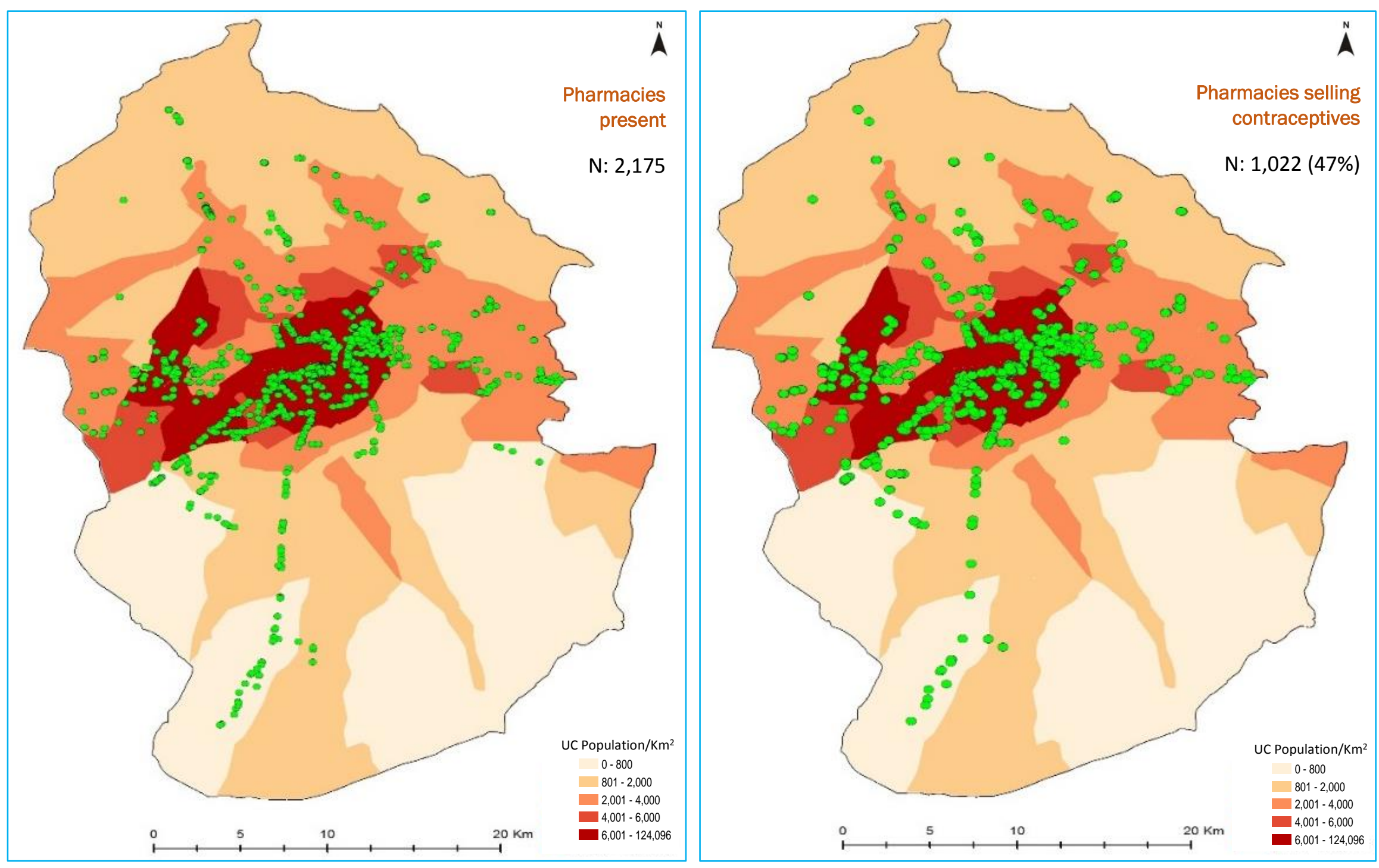


\section{Consumer Perspectives on Barrlers to Use of Family Planning}

During the landscape assessment, in-depth interviews (IDIs) were conducted with 13 men and 49 women in nine urban and six rural communities in Peshawar. In addition, 7 focus group discussions (FGDs) were conducted, including 3 with men and 4 with women. Views from a total of 127 men and women were collected through these interactions.

Among the barriers to family planning identified, the largest four were lack of information and services for men; limitations of access, influencing method use; mobility issues among women; and cost of services, affecting poor users. Peshawar was the only study district where doubts about religious permissibility were also a barrier, albeit not as strongly as the four mentioned earlier. To a lesser extent, poor quality of services at public health facilities was also an obstacle for users.

\section{Lack of information and services for both urban and rural men}

- Men have no direct contact with the health system or service providers for discussing family planning.

- Cultural norms and shyness discourage them from discussing family planning with others; they can discuss it only with close friends or wives.

"We (men) do not go to the family health center but our women get information regarding use of family planning methods from there. My wife shares this information with me. In our area, we can only discuss use of family planning methods with very close friends". Male, Peshawar city

- Purchasing condoms is a challenge for men; they feel embarrassment in buying them and prefer not to buy from shops where they are known, to keep their own use private

"Generally in this community people feel shy in talking about such matters. Mostly people come to buy condoms, but they feel shy doing so. They even keep their gaze lowered while purchasing it." Male shopkeeper, Peshawar rural

"It is embarrassing! I don't like to buy condoms from the shops in the neighborhood. All the shopkeepers know me, so I don't feel comfortable. I know it is available in every shop." Male, Peshawar rural
Access issues, compounded by restricted female mobility, in both urban and rural areas

- Access limitations are influencing method choices in both rural and urban areas in Peshawar. The district has a traditional society, and women are not allowed to go out frequently, especially if unaccompanied. Therefore, women mainly prefer methods that are provided by LHWs at their doorstep, i.e., condoms, oral contraceptive pills, and injectables.

- Due to limited mobility, women also have little knowledge about facilities where they can get other methods.

- Women feel reluctant going to health facilities located at a distance because they cannot go there unaccompanied and they cannot leave their children unattended.

"Our men do not give us permission to go outside. The LHW comes to our homes and we easily get information from her. So I thought that I would get this method at home, through the LHW. Her home is right in front of mine." Female, Peshawar rural

"The hospital was far away and my husband and I had to walk across many fields to get there, as there was no road. Also, we live alone; there is no one to leave my disabled child with." Female, Peshawar rural

- At times, women use IUDs or implants just because of the camps that are arranged in or near their communities by NGOs (MSS)

- While couples' choices may be restricted to what is offered by LHWs and camps arranged by NGOs, the fact is that these are the only accessible sources for them in the restrictive environment of Peshawar-and as such, LHWs in particular, are held in very high esteem and regarded as a blessing.

“Only Baji (LHW) goes to people's homes and provides them the family planning methods they need, such as pills. In the entire area, only she is providing family planning services. There is no other source." Female, Peshawar city

"I am not allowed to go outside the house. There is an NGO; their workers visit door to door and ask women if they are using any method or not. One visits me as well. I also discuss the methods 
with her-which is a good and which is bad." Female, Peshawar city

\section{Cost-a major barrier for poor couples everywhere}

- Although condoms, pills and injectable are provided by LHWs, stocks can run out, and then purchasing condoms from the market is difficult - for some couples, the opportunity cost is measured in food.

"The condom available in the market costs Rs. 120, which is difficult to afford. We skip an item from the daily meal when we need to buy a condom....like we don't buy yogurt that day." Female, Peshawar city

- The costs of services and products in the private sector are a major barrier for the poor regardless of where they reside; however, for rural couples, travel is an additional burden

"We are poor people. We can't afford it (IUD); it is expensive. If it had not been available free of cost, I probably would not have used it because I wouldn't have been able to arrange the money." Female, Peshawar rural

- Repeated visits for the management of side effects can pose a heavy financial burden on all users.
Confusion about the Islamic position on family planning, among urban and rural couples

- Peshawar has a conventional society and people are influenced by local maulvis (clerics), who often have a negative view of family planning.

- Couples are confused: they want to use family planning, are confused about the Islamic position, and hindered by maulvis' negative verdicts.

- Sometimes, their economic situation and related pressing issues override the question of permissibility

"I do not have enough Islamic information about FP. If maulvis like anything, they consider it right according to Islam. And if they do not like it, they give a ruling against it and then if someone adopts it they consider it the way of the infidel. I have not had any direct discussion with any maulvi on this topic but behind my house there is mosque and its maulvi is against family planning." Male, Peshawar rural

"We go to offer prayers or Jummah prayers, and the maulvi talks of family planning as a sin. But then we see our life's problems and we practice family planning. When friends talk about its benefits, we adopt family planning." Male, Peshawar city 


\section{District specific Donors, Projects and Implementing partners}

\begin{tabular}{|c|c|c|}
\hline Donor & Program/ Project Title & Implementing Partner \\
\hline DFID & Delivering Reproductive Health Results (DRHR), 2012-2017 & $\begin{array}{l}\text { Population Services International (PSI)/ Greenstar Social } \\
\text { Marketing (GSM) } \\
\text { Marie Stopes International: Reproductive Health Franchise } \\
\text { DKT International/Pakistan }\end{array}$ \\
\hline $\begin{array}{l}\text { Bill and Melinda } \\
\text { Gates Foundation }\end{array}$ & Landscape Analysis of Family Planning in Pakistan, 2015-2016 & Population Council \\
\hline $\begin{array}{l}\text { The David \& Lucile } \\
\text { Packard Foundation }\end{array}$ & Achieving MDG5 - Continuing Momentum, Building Champions, 2012-2015 & Shirkat Gah Women Resource Centre \\
\hline USAID & DELIVER Project, 2008-2016 & $\begin{array}{l}\text { Planning Commission of Pakistan } \\
\text { Ministry of Health (MOH) } \\
\text { Provincial and regional departments of health and } \\
\text { population } \\
\text { UNFPA } \\
\text { NGOs }\end{array}$ \\
\hline \multirow{3}{*}{ UNFPA } & Public Private Partnership in Provision of FP Services, 2014-2017 & $\begin{array}{l}\text { MSS } \\
\text { Population Welfare Departments }\end{array}$ \\
\hline & $\begin{array}{l}\text { Capacity Building of Female Service Providers Enhanced in Family Planning, } \\
\text { 2014-2017 }\end{array}$ & $\begin{array}{l}\text { Population Welfare Departments } \\
\text { MNCH Programs } \\
\text { LHWs Program }\end{array}$ \\
\hline & $\begin{array}{l}\text { Advocacy for Universal Access to Reproductive Health and to Integrate in } \\
\text { Provincial Health Policies, Plans and Budgetary Frameworks, 2012-2017 }\end{array}$ & $\begin{array}{l}\text { Population Welfare Departments } \\
\text { Population Council } \\
\text { Pathfinder } \\
\text { Ministry of National Health Services, Regulations and } \\
\text { Coordination }\end{array}$ \\
\hline WHO & $\begin{array}{l}\text { Providing Technical Assistance to the Country for the Development of a Unified } \\
\text { Care Providers Manual on FP based on the WHO Handbook on FP }\end{array}$ & $\begin{array}{l}\text { Ministry of National Health Services Coordination and } \\
\text { Regulation } \\
\text { MNCH programs } \\
\text { UNFPA, Population Council, GIZ, USAID }\end{array}$ \\
\hline $\begin{array}{l}\text { Large Anonymous } \\
\text { Donor (LAD) }\end{array}$ & $\begin{array}{l}\text { Increasing Access to and Use of Long Term Methods of FP and PAC Services in } \\
\text { Pakistan, 2014-16 }\end{array}$ & Greenstar Social Marketing \\
\hline
\end{tabular}

